DOI: https://doi.org/10.33330/jurteksi.v6i2.528

Available online at http://jurnal.stmikroyal.ac.id/index.php/jurteksi

\title{
PENERAPAN METODE ANALYTICAL HIERARCHY PROCESS DALAM PEMILIHAN BIBIT JAGUNG UNGGUL
}

\author{
Zulfi Azhar \\ Sistem Informasi, Sekolah Tinggi Manajemen Informatika Komputer Royal \\ email: zulfi_azhar@yahoo.co.id
}

\begin{abstract}
The use is still the traditional way by trying corn seeds planted by farmers in Tanjungbalai in Asahan Regency. Farmers will choose maize seeds that are fast growing, but will have poor yields on fruit size, resulting in less satisfactory yields. As a result a problem arises that will occur in the absence of determining a number of criteria that can get quality corn seeds. Farmers are not familiar with the use of technology in getting good corn seeds. This requires the use of a system that is able to answer and provide solutions in the selection of corn seeds using a number of criteria and alternatives to superior corn seeds. This research uses AHP method decision support system with comparison of criteria and alternatives in the selection of superior corn seeds in producing the best alternative.
\end{abstract}

Keywords: AHP, alternatives, criteria, farmers superior corn seeds

\begin{abstract}
Abstrak: Penggunaan masih cara yang tradisional dengan mencoba bibit jagung yang di tanam oleh para petani di Tanjungbalai di Kabupaten Asahan. Petani akan memilih bibit jagung yang waktu tanamnya cepat, namun akan memiliki menghasilkan yang kurang baik pada ukuran buah mengakibatkan hasil produksi menjadi kurang memuaskan. Akibatnya timbul suatu masalah yang akan terjadi dengan tidak adanya penentuan sejumlah kriteria yang bisa mendapatkan bibit jagung yang berkualitas. Para petani kurang paham dengan penggunaan teknologi dalam mendapatkan bibit jagung yang bagus. Hal ini diperlukan penggunaan sistem yang mampu menjawab dan memberikan solusi dalam pemilihan bibit jagung menggunakan sejumlah kriteria dan alternatif bibit jagung unggul. Penelitian ini menggunakan sistem pendukung keputusan metode AHP dengan perbandingan kriteria dan alternatif pada pemilihan bibit jagung yang unggul dalam menghasilkan sebuah alternatif yang terbaik.
\end{abstract}

Kata kunci: AHP, alternatif, bibit jagung unggul, kriteria, petani

\section{PENDAHULUAN}

Tanaman jagung banyak ditanam para petani karena tanaman ini menghasilkan karbohidrat tinggi seperti gandum atau padi. Para petani dalam menanam jagung penggunaannya masih cara yang tradisional dengan mencoba bibit jagung yang di tanam oleh para petani di 
JURTEKSI (Jurnal Teknologi dan Sistem Informasi)

Vol. 6 No. 2, April 2020, hlm. 145 - 154

DOI: https://doi.org/10.33330/jurteksi.v6i2.528

Available online at http://jurnal.stmikroyal.ac.id/index.php/jurteksi

Tanjungbalai di kabupaten Asahan. Petani memilih bibit jagung yang waktu tanamnya cepat, namun akan memiliki menghasilkan yang kurang baik pada ukuran buah mengakibatkan hasil produksi menjadi kurang memuaskan. Pemilihan bibit masih menggunakan cara mencoba saja dari jenis beberapa bibit jagung. Akibatnya waktu tanam lebih lama, ukuran tongkol jagung yang tidak sesuai, hingga bisa panen gagal. Beberapa petani memilih bibit jagung yang waktu tanamnya cepat, tetapi menghasilkan kurang baik pada ukuran buah dan hasil produksi kurang maksimal. Pemilihan bibit jagung yang ukuran buah besar namun tidak bisa beradaptasi pada perubahan cuaca dan hasilnya tidak memiliki kualitas dan menyebabkan harga jual turun.

Dengan tidak adanya pemilihan kriteria dalam menentukan bibit jagung berkualitas serta kurang paham para petani dengan penggunaan teknologi dalam menentukan bibit jagung yang bagus sehingga hasil panen tidak memuaskan. Hal ini maka perlu penggunaan sistem yang dapat memberikan jawaban permasalahan dengan sejumlah kriteria dan alternatif yang ditentukan. Penelitian ini menggunakan sistem pendukung keputusan dengan metode AHP dengan perbandingan berdasarkan kriteria dan alternatif pada penentuan bibit jagung yang unggul.

Metode AHP mampu menganalisis faktor kriteria yang prioritas dalam pemilihan perumahan KPR yang. Dalam perhitungan analisis yang dilakukan ini secara peringkat adalah kriteria prioritas yang tertinggi terdiri atas kriteria kualitas bangunan, harga
ISSN 2407-1811 (Print)

ISSN 2550-0201 (Online) rumah, uang muka, lokasi, perizinan dan fasilitas[1]. Penggunaan AHP dapat menganalisis memilih produksi ikan air tawar di pembibitan ikan Dwi Mutiara. Bagi pengelola dan penjual pada pembibitan ikan dapat memberikan solusi ikan air tawar yang ekonomis dan menguntungkan dalam pembibitan, pemeliharan dan penjualan berdasarkan kriteria yang ada yang terpilih yaitu ikan lele, ikan gabus, ikan gurami dan ikan mas[2].

Metode AHP juga mampu menganalisis pada pemilihan mata kuliah praktek di STMIK Royal Kisaran, dengan menggunakan sejumlah alternatif dari beberapa kriteria yang mempengaruhi dalam pemilihan matakuliah praktek di laboratorium terdiri dari pemahaman program, pemahaman teori, pengajar/ dosen, tugas praktek, waktu praktek dan modul pembelajaran[3]. Penggunaan metode AHP dapat juga menganalisis faktor/kriteria prioritas dalam pemilihan bibit jagung unggul bagi para petani di Tanjung Balai Kabupaten Asahan, Berdasarkan dari hasil analisis perhitungan yang telah dilakukan, secara berurutan kriteria yang prioritas tertinggi yaitu kriteria ketahanan terhadap hama, hasil produksi , ukuran buah, waktu panen dan adaptasi lingkungan[4].

Penerapan Metode Analytical Hierarchy Process pada kenaikan pangkat yang dibuat untuk menentukan layak tidaknya kenaikan pangkat diberikan kepada pegawai. Langkah yang dilakukan dalam AHP (menyusun hirarki, menentukan prioritas antar element, sintesis, mengukur konsistensi). Hasil akhir dari dalam SPK kenaikan pangkat ini 
JURTEKSI (Jurnal Teknologi dan Sistem Informasi)

Vol. 6 No. 2, April 2020, hlm. 145 - 154

DOI: https://doi.org/10.33330/jurteksi.v6i2.528

Available online at http://jurnal.stmikroyal.ac.id/index.php/jurteksi

menentukan proses kenaikan pangkat dengan menggunakan sejumlah kriteria terdiri atas orientasi pelayanan, integritas, disiplin, komitmen, kerjasama dan kepemimpinan[5]. Pensiun pegawai diberikan sebagai jaminan hari tua dan sebagai penghargaan atas jasa-jasa pegawai negeri selama bertahun-tahun bekerja dalam pemerintahan, ada berbagai jenis pemensiuan pegawai yang di atur oleh Peraturan Pemerintah nomor 5 tahun 2014 umumnya pemensiuan pegawai yang sering didengar ada 3 jenis yaitu : pensiun karena batas usia pensiun, pensiun atas permintaan sendiri, pensiun karena meninggal dunia. Dan setiap jenis pemensiun diatas memiliki beberapa kriteria, pada pensiun karena batas usia pegawai harus berusia 58th. Sedangkan untuk pensiun atas permintaan sendiri memiliki 3 kriteria yaitu pegawai harus kurang lebih berusia 50th, pegawai sudah mengabdikan diri kepada pemerintah 20th dan pegawai tidak terkait tindak pidana. Dan untuk pensiun karena meninggal dunia otomatis pegawai tersebut pensiun. Dengan adanya Sistem Pendukung Keputusan (SPK) ini dapat membatu pihak-pihak yang terkait dan mempersingkat pemen-siunan dengan kriteria yang sudah di beri bobot[6].

Penelitian ini memberikan solusi bahwa metode AHP dapat digunakan dalam penilaian kompetensi soft skill karyawan sampai menentukan nilai prioritas karyawan tertinggi dengan menggunakan sejumlah kriteria yaitu komunikasi, kerja sama, kejujuran dan interpersonal[7]. Sistem pendukung keputusan dapat digunakan sebagai alat untuk mengevaluasi atas kinerja karyawan yaitu dengan menggunakan salah satu metode dalam sistem pendukung keputusan. Metode yang digunakan yaitu AHP, dapat menampilkan peringkat sepuluh besar karyawan berprestasi melalui grafik yang di tampilkan dalam aplikasi dengan menggunakan kriteria penilaian kinerja, score TOEIC dan kehadiran karyawan[8]. Dengan metode AHP dapat membantu untuk pencapaian kegiatan promosi karyawan pada PT. Selular Global net Medan secara maksimal berdasarkan pada dekomposisi masalah menjadi sebuah struktur hirarki yang terdiri dari tujuan, kriteria yaitu disiplin, tanggung jawab. inisiatif, kerjasama, prestasi kerja dan prilaku dengan sejumlah alternatif pilihan[9]. Sistem melakukan penilaian terhadap tes psikologi kepribadian calon karyawan, diasumsikan mencakup kriteriakriteria antara lain motivasi, percaya diri, kejujuran, kepedulian, loyalitas. Sistem akan melakukan analisis dan penilaian terhadap hasil tes kepribadian calon karyawan. Hasil penelitian ini adalah model sistem pendukung keputusan seleksi calon karyawan berdasar hasil tes psikologi, sehingga pemilihan calon karyawan yang tepat untuk menjadi karyawan perusahaan sesuai dengan posisi yang dibutuhkan perusahaan[10].

Dalam membantu pengambilan keputusan dari sejumlah pilihan diperlukan sistem, memberikan solusi akhir pilihan yang terbaik.

Sistem pendukung keputusan bagian dari Artifical Intelligence yang digunakan untuk memberikan jawaban dari proses perhitungan dari sejumlah 
JURTEKSI (Jurnal Teknologi dan Sistem Informasi)

Vol. 6 No. 2, April 2020, hlm. 145 - 154

DOI: https://doi.org/10.33330/jurteksi.v6i2.528

Available online at http://jurnal.stmikroyal.ac.id/index.php/jurteksi

pilihan dengan tujuan tertentu. Manfaat SPK memperluas, membantu, menghasilkan solusi stimulan bagi pengambil keputusan dalam memahami persoalannya dengan menyajikan berbagai alternatif pemecahan[11][12]. Pengambilan keputusan dalam pembuat keputusan manajemen dari masalah semi terstruktur[13].

Penggunaan metode AHP menerapkan pendekatan matematis yang kompleks, pendekatan kualitatif dapat diterima semua stake holder dan pengelola program[14]. Penggunaan AHP memerlukan sejumlah kriteria yang dicari berdasarkan tujuannya. Sejumlah alternatif adalah pilhan yang akan ditentukan melalui proses perhitungan. Sistem pada AHP lebih sederhana dan efektif dalam penggunaan pengambilan hasil yang terbaik. Pengetahuan yang terinci dalam menyusun realitas yang kompleks kedalam bagian elemen pokok, kemudian dibagi kedalam bagian-bagiannya lagi, secara hierarki[15][16].

Dalam aturan AHP yaitu:

- Permasalahan didefinisikan seperti apa yang terjadi dan diberi bagianbagian secara hierarki secara tersusun.

- Penentukan prioritas dengan penggunaan matriks yang berpasangan

- Sintesis

Perbandingan yang dibuat secara matriks dalam memberikan hasil yang prioritas.

- Pengukuran konsistensi

Pengukuran konsistensi berdasarkan formula yang disesuaikan dengan aturan pada tabel yang telah ditentukan.
ISSN 2407-1811 (Print)

ISSN 2550-0201 (Online)
- Mencari nilai Consistency Index yaitu:

$\mathrm{CI}=(\lambda$ maks $-\mathrm{n}) / \mathrm{n}-1$

$\mathrm{n}=$ sejumlah elemen

$\lambda$ maks $=$ angka eigen maksimum dari matriks perbandingan yang berpasangan

- Mencari nilai Rasio Konsistensi yaitu :

$\mathrm{CR}=\mathrm{CI} / \mathrm{RI}$

$$
\begin{aligned}
\text { yaitu } \mathrm{CR} & =\text { Rasio Consistency, } \\
\mathrm{CI} & =\text { Indeks Consistency, } \\
\mathrm{RI} & =\text { Indeks secara Random }
\end{aligned}
$$

- Pengecheckan nilai konsistensi hirarki.

Nilai konsistensi hirarki lebih besar $10 \%$, data penilaian konsistensi mesti diperbaiki.

$\mathrm{CR}<0,1$

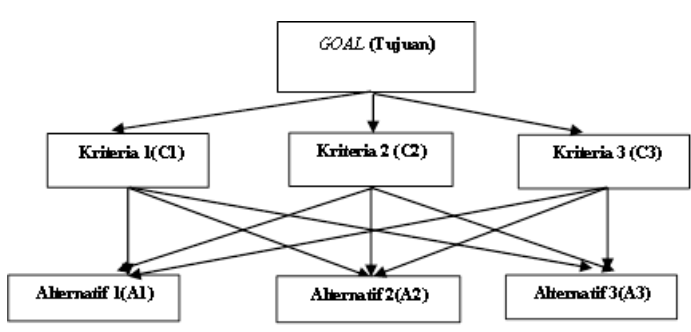

Gambar 1. Struktur Hierarki Pada Metode AHP

Bibit jagung disebutkan unggul berdasarkan kualitasnya yang baik dengan sejumlah kriteria seperti dalam bentuk buah, akar, produktivitas, warna daunnya, tahan terhadap hama Pemilihan bibit jagung yang optimal memberikan hasil yang memuaskan.

Berikut beberapa varietas jagung yang dikeluarkan Kementrian Pertanian diantanya adalah:

- Talango

- DMI

- Bima 7

- Pertiwi 1

- Bisi 18

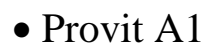


JURTEKSI (Jurnal Teknologi dan Sistem Informasi)

Vol. 6 No. 2, April 2020, hlm. 145 - 154

DOI: https://doi.org/10.33330/jurteksi.v6i2.528

Available online at http://jurnal.stmikroyal.ac.id/index.php/jurteksi

\section{METODE}

Metode menggunakan beberapa tahap yaitu:

a. Mengumpulkan Dokumen Data

Formulir isian diberikan kepada 35 petani Tanjung Balai di Kabupaten Asahan. Formulir ini diisi petani sesuai dengan perbandingan antara kriteria dan juga alternatif. Dokumen data dikumpulkan hasil penilaian dari para petani Tanjung Balai di Kabupaten Asahan yang berjumlah 35 petani.

b. Penganalisaan Data

Penganalisaan data dengan memasukkan beberapa kriteria yang ditetapkan dengan beberapa alternatif pilihan yang dipilih dalam mencapai goal yang direncanakan.

c. Menggunakan proses uji pada Sistem

Menggunakan aplikasi matrix excel, pada proses uji secara perhitungan metode AHP yang dilakukan dengan perhitungan pada sistem. Dengan menggunakan rumus perhitungan AHP dan hasilnya Consistency Ratio lebih kecil dari 0,1
ISSN 2407-1811 (Print)

ISSN 2550-0201 (Online)
Tabel 1. Nilai Secara Hierarki

\begin{tabular}{|c|c|c|}
\hline Nilai & Artinya & Keterangan \\
\hline 1 & $\begin{array}{l}\text { Sama-sama } \\
\text { penting }\end{array}$ & $\begin{array}{l}\text { Punya pengaruh } \\
\text { yang sama }\end{array}$ \\
\hline 3 & $\begin{array}{l}\text { Sedikit } \\
\text { penting }\end{array}$ & $\begin{array}{l}\text { Perbandingan } \\
\text { sedang dari lainnya }\end{array}$ \\
\hline 5 & Lebih penting & $\begin{array}{l}\text { Perbandingan lebih } \\
\text { dari lainnya }\end{array}$ \\
\hline 7 & $\begin{array}{l}\text { Sangat } \\
\text { penting }\end{array}$ & $\begin{array}{l}\text { Perbandingan sangat } \\
\text { lebih dari lainnya }\end{array}$ \\
\hline 9 & $\begin{array}{l}\text { Mutlak } \\
\text { penting }\end{array}$ & $\begin{array}{l}\text { Perbandingan sangat } \\
\text { kuat dari lainnya }\end{array}$ \\
\hline $\begin{array}{r}2,4 . \\
6.8\end{array}$ & $\begin{array}{c}\text { Nilai } \\
\text { diantaranya }\end{array}$ & $\begin{array}{l}\text { Penilaian } \\
\text { berdekatan }\end{array}$ \\
\hline
\end{tabular}

\section{HASIL DAN PEMBAHASAN}

Data dikumpulkan dari lapangan dengan memilih dari sejumlah kriteria dengan menggunakan formulir pengisian untuk penilaian. Para petani di Tanjung Balai diminta untuk membandingkan dari sejumlah kriteria yang diperlukan. Sejumlah kriteria yang berpengaruh pada pemilihan bibit jagung unggul: Adaptasi Lingkungan (C1), Hasil produksi (C2), Ketahanan terhadap hama (C3), Ukuran buah (C4) dan Waktu panen (C5).

Tabel 2. Perhitungan Kriteria

\begin{tabular}{cccccc}
\hline Kriteria & C1 & C2 & C3 & C4 & C5 \\
\hline C1 & 1 & 0,2 & 0,2 & 0,333 & 0,333 \\
\hline C2 & 5 & 1 & 0,333 & 3 & 3 \\
\hline C3 & 5 & 3 & 1 & 3 & 5 \\
C4 & 3 & 0,333 & 0,333 & 1 & 3 \\
C5 & 3 & 0,333 & 0,2 & 0,333 & 1 \\
Jumlah & 17 & 4,867 & 2,067 & 7,667 & 12,333 \\
\hline
\end{tabular}


JURTEKSI (Jurnal Teknologi dan Sistem Informasi)

Vol. 6 No. 2, April 2020, hlm. 145 - 154

DOI: https://doi.org/10.33330/jurteksi.v6i2.528

Available online at http://jurnal.stmikroyal.ac.id/index.php/jurteksi

Tabel 3. Kriteria Normalisasi

\begin{tabular}{ccccccc}
\hline Kriteria & C1 & C2 & C3 & C4 & C5 & Jumlah \\
\hline C1 & 0,059 & 0,041 & 0,097 & 0,043 & 0,027 & 0,267 \\
\hline C2 & 0,294 & 0,205 & 0,161 & 0,391 & 0,243 & 1,295 \\
\hline C3 & 0,294 & 0,616 & 0,484 & 0,391 & 0,405 & 2,191 \\
C4 & 0,176 & 0,068 & 0,161 & 0,130 & 0,243 & 0,780 \\
C5 & 0,176 & 0,068 & 0,097 & 0,043 & 0,081 & 0,466 \\
Jumlah & 1 & 1 & 1 & 1 & 1 & 5 \\
\hline
\end{tabular}

Tabel 4. Prioritas dan Perangkingan

\begin{tabular}{cccc}
\hline Kriteria & Nilai Prioritas & $\begin{array}{c}\text { Prioritas } \\
\text { (Persentase) }\end{array}$ & Perangkingan \\
\hline C1 & 0,053 & 5,3 & 5 \\
\hline C2 & 0,259 & 25,9 & 2 \\
C3 & 0,438 & 43,8 & 1 \\
C4 & 0,156 & 15,6 & 3 \\
C5 & 0,093 & 9,3 & 4 \\
Jumlah & 1 & 100 & \\
\hline
\end{tabular}

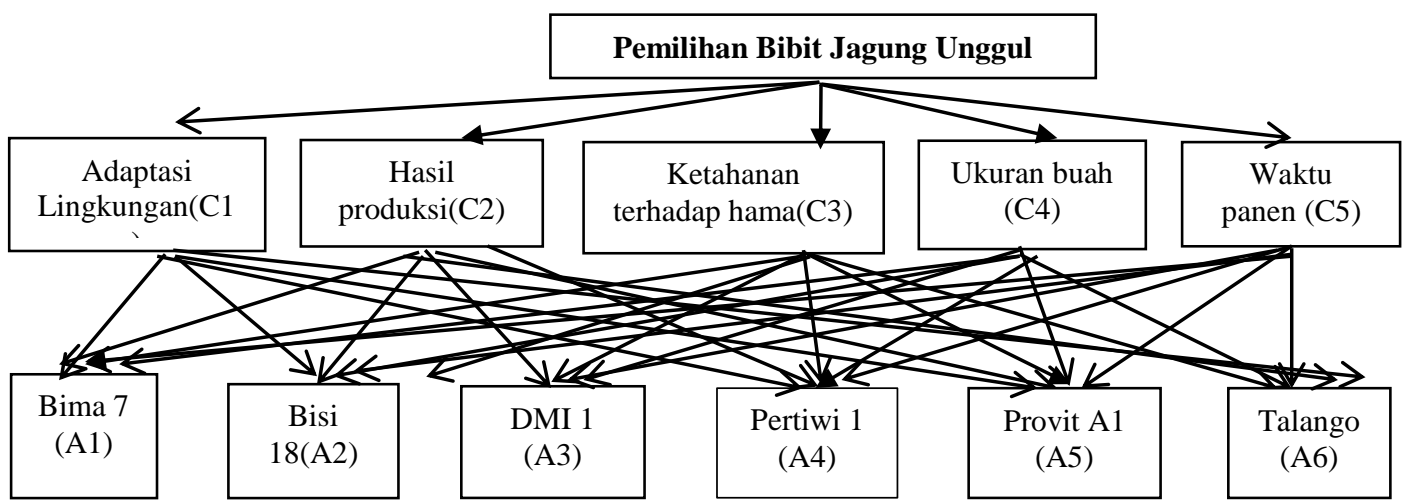

Gambar 2. Struktur Pemilihan Bibit Jagung Unggul Secara Hierarki

Penilaian kriteria dinyatakan benar (konsisten) jika terpenuhinya nilai Consistency Ratio

$(\mathrm{CR})<0,1$.

Rasio Konsistensi/Consistency Ratio $(\mathrm{CR})=\mathrm{CI} / \mathrm{IR}$

$\mathrm{CR}=$ Consistency Ratio

$\mathrm{CI}=$ Consistency Index

$\mathrm{RI}=$ Random Index
$\mathrm{CI}=(\lambda$ maks- $\mathrm{n}) / \mathrm{n}-1$,

$\mathrm{n} \quad=$ jumlah elemen

$\lambda$ maks $=$ hasil nilai eigen maksimum dari matriks pairwise comparisons.

Hasil nilai eigen maksimum ( $\lambda$ maksimum) dengan penjumlahan pada hasil perkalian jumlah pada tabel 2 dengan kolom prioritas pada tabel 4. Hasil nilai eigen maksimum 
JURTEKSI (Jurnal Teknologi dan Sistem Informasi)

Vol. 6 No. 2, April 2020, hlm. 145 - 154

DOI: https://doi.org/10.33330/jurteksi.v6i2.528

Available online at http://jurnal.stmikroyal.ac.id/index.php/jurteksi

yaitu :

$$
\begin{aligned}
\lambda \text { maks }= & (17 * 0,053)+(4,867 * 0,259) \\
& +(2,067 * 0,438) \\
& +(7,667 * 0,156) \\
& +(12,333 * 0,093) \\
= & 5,421 \\
\mathrm{CI} \quad= & (5,421-5) / 5-1=0,105283
\end{aligned}
$$

Penentuan nilai RI dari jumlah kriteria (n) pada tabel 5. Jumlah kriteria adalah 5 , nilai $\mathrm{RI}=1,12$ Maka nilai $\mathrm{CR}=\mathrm{CI} / \mathrm{IR}=$ $0,105283 / 1,12=0,094002679$.

Hasil Nilai $\mathrm{CR}=0,094002679$ adalah memenuhi syarat, $\mathrm{CR}<0,1$. Dapat dijelaskan bahwa penentuan kriteria yang mempengaruhi pemilihan bibit jagung unggul dinyatakan sudah konsisten/benar.

Pada matriks perbandingan alternatif dengan kriteria yang terpilih yaitu Ketahanan terhadap hama (C3). Alternatif dalam pemilihan bibit jagung unggul adalah : Bima 7 (A1), Bisi 18(A2), DMI 1(A3), Pertiwi 1(A4), Provit A1(A5) dan Talango(A6).

Hasil nilai eigen maksimum ( $\lambda$ maksimum), tabel 6 dengan menjumlahkan pada hasil perkalian jumlah pada kolom matriks prioritas pada tabel 8 .$$
\text { yaitu : }
$$
Untuk nilai $\mathrm{CR}$, (konsisten).

perbandingan alternatif dengan kolom

$$
\begin{aligned}
\lambda \text { maks } & =(10 * 0,180)+(2,533 * 0,335) \\
& +(13,333 * 0,093) \\
& +(8,167 * 0,159) \\
& +(10,667 * 0,128) \\
& +\left(12,333^{*} 0,105\right) \\
& =6,548 \\
\mathrm{CI} \quad & =(6,548-6) / 6-1 \\
& =0,109639417
\end{aligned}
$$$$
\text { Hasil nilai eigen maksimum }
$$

Penetuan nilai RI, dari jumlah elemen alternatif (n). Jumlah elemen alternatif adalah 6 maka $\mathrm{n}=6$, angka $\mathrm{RI}=1,24$.

$$
\begin{aligned}
\mathrm{CR} & =0,109639417 / 1,24 \\
& =0,088418884 .
\end{aligned}
$$

Hasil penilaian pada $\mathrm{CR}=$ 0,088418884 sudah memenuhi syarat, $\mathrm{CR}<0,1$ pada proses penentuan pemilihan kriteria pada bibit jagung unggul dapat dinyatakan benar

Hasil akhir dari pengujian ini bahwa pemilihan bibit jagung unggul berdasarkan kriteria ketahanan terhadap hama(C3) adalah Alternatif ke-2 (A2) yaitu Bisi 18 yang terpilih menurut kriteria yang terpilih.

Tabel 6. Perhitungan Alternatif

\begin{tabular}{ccccccc}
\hline Alternatif & A1 & A2 & A3 & A4 & A5 & A6 \\
\hline A1 & 1 & 0,2 & 3 & 3 & 3 & 0,333 \\
A2 & 5 & 1 & 3 & 3 & 3 & 3 \\
A3 & 0,333 & 0,333 & 1 & 0,333 & 0,333 & 3 \\
A4 & 0,333 & 0,333 & 3 & 1 & 3 & 2 \\
A5 & 0,333 & 0,333 & 3 & 0,333 & 1 & 3 \\
A6 & 3 & 0,333 & 0,333 & 0,5 & 0,333 & 1 \\
Jumlah & 10 & 2,533 & 13,333 & 8,167 & 10,66 & 12,333 \\
& & & & & 7 & \\
\hline
\end{tabular}


DOI: https://doi.org/10.33330/jurteksi.v6i2.528

Available online at http://jurnal.stmikroyal.ac.id/index.php/jurteksi

Tabel 7. Alternatif Normalisasi

\begin{tabular}{cccccccc}
\hline Alternatif & A1 & A2 & A3 & A4 & A5 & A6 & Jumlah \\
\hline A1 & 0,100 & 0,079 & 0,225 & 0,367 & 0,281 & 0,027 & 1,080 \\
A2 & 0,500 & 0,395 & 0,225 & 0,367 & 0,281 & 0,243 & 2,012 \\
A3 & 0,033 & 0,132 & 0,075 & 0,041 & 0,031 & 0,243 & 0,555 \\
A4 & 0,033 & 0,132 & 0,225 & 0,122 & 0,281 & 0,162 & 0,956 \\
A5 & 0,033 & 0,132 & 0,225 & 0,041 & 0,094 & 0,243 & 0,768 \\
A6 & 3 & 0,132 & 0,025 & 0,061 & 0,031 & 0,081 & 0,630 \\
Jumlah & 1 & 1 & 1 & 1 & 1 & 1 & 6 \\
\hline
\end{tabular}

Tabel 8. Prioritas dan Perangkingan

\begin{tabular}{cccc}
\hline Alternatif & Prioritas & $\begin{array}{c}\text { Prioritas } \\
\text { (Persentase) }\end{array}$ & Perangkingan \\
\hline A1 & 0,180 & 18 & 2 \\
A2 & 0,335 & 33,5 & 1 \\
A3 & 0,093 & 9,3 & 6 \\
A4 & 0,159 & 15,9 & 3 \\
A5 & 0,128 & 12,8 & 4 \\
A6 & 0,105 & 10.5 & 5 \\
Jumlah & 1 & & \\
\hline
\end{tabular}

\section{SIMPULAN}

Hasil akhir pada penelitian ini bahwa Metode AHP memberikan solusi alternatif pada pemilihan bibit jagung unggul bagi para petani di Tanjung Balai. Penilaian alternatif akan lebih optimal dengan pemilihan kriteria yang lebih banyak dan lebih objektif. Dengan menggunakan metode AHP ini para petani mampu mengimplementasikan secara ilmu pengetahuan dalam menentukan bibit jagung unggul yang yang berkualitas.

\section{DAFTAR PUSTAKA}

[1] Z. Azhar and M. Handayani, "ANALISIS FAKTOR PRIORITAS DALAM PEMILIHAN PERUMAHAN KPR MENGGUNAKAN METODE AHP," J. Manaj. Inform. dan Sist. Inf., 2018, doi: 10.36595/misi.v1i2.38.

[2]

Z Azhar, "ANALISIS PEMILIHAN PRODUKSI IKAN AIR TAWAR DI DWI," 2019.

[3] Z. Azhar, "Analisis Pemilihan Mata Kuliah Praktek Menggunakan Metode AHP," Pros. Semin. Nas. Ris. Inf. Sci., 2019, doi: 
DOI: https://doi.org/10.33330/jurteksi.v6i2.528

Available online at http://jurnal.stmikroyal.ac.id/index.php/jurteksi

10.30645/senaris.v1i0.126.

[4] Z. Azhar, "Faktor Analisis Prioritas Dalam Pemilihan Bibit Jagung Unggul Menggunakan Metode AHP," pp. 347-350, 2020.

[5] R. A. Suherdi, R. Taufiq, A. A. Permana, P. S. Informatika, F. Teknik, and U. M. Tangerang, "Penerapan Metode AHP dalam Sistem Pendukung Keputusan Kenaikan Pangkat Pegawai Di Badan Kepegawaian Dan Pengembagan Sumber Daya Manusia Kota Tangerang," Sintak, 2018.

[6] I. A. Susila and R. Taufiq, "Penerapan Metode Analytical Heirarchy Process (Ahp) Dalam Sistem Pendukung Keputusan (Spk) Pemensiunan Pada Badan Kepegawaian Dan Pengembangan Sumber Daya Manusia Kota Tangerang," Pros. SINTAK 2018, 2018.

[7] R. Umar, A. Fadlil, and Y. Yuminah, "Sistem Pendukung Keputusan dengan Metode AHP untuk Penilaian Kompetensi Soft Skill Karyawan," Khazanah Inform. J. Ilmu Komput. dan Inform., 2018, doi: 10.23917/khif.v4i1.5978.

[8] L. O. Iwan Rijayana1), "SISTEM PENDUKUNG KEPUTUSAN PEMILIHAN KARYAWAN BERPRESTASI BERDASARKAN KINERJA MENGGUNAKAN METODE ANALITYC HIERARCY PROCESS," Semin. Nas. Inform. 2012 (semnasIF 2012) UPN"Veteran" Yogyakarta, 30
Juni 2012, 1986.

[9] Iskandar and E. S. Pasaribu, "Sitem Pendukung Keputusan Promosi Jabatan Karyawan Dengan Metode Analytycal Hierarchy Process (AHP) Studi Kasus Pada PT.Selular Global Net Medan," Teknol. Dan Sist. Inf., 2015.

[10] "Sistem Pendukung Keputusan Seleksi Calon Karyawan Berdasarkan Hasil Tes Psikologi Kepribadian Menggunakan Metode Ahp (Studi Kasus Di Kalimasada)," 2014, doi: 10.30873/ji.v14i1.509.

[11] M. A. Sembiring and Z. Azhar, "Factors Analysis And Profit Achievement For Trading Company By Using Rough Set Method," Int. J. Artif. Intell. Res., Jun. 2017, doi: 10.29099/ijair.v1i1.15.

[12] S. dan W. Mohammad Taufan AZ, "Sistem Pendukung Keputusan untuk Investasi Perumahan Area Malang Menggunakan $\mathrm{P}$ Algoritma Bayesian," J. EECCIS, 2014.

[13] Priranda Widara Ananta and Sri Winiarti, "Sistem Pendukung Keputusan Dalam Penilaian Kinerja Pegawai Untuk Kenaikan Jabatan Pegawai Menggunakan Metode Gap Kompetisi," J. Sarj. Tek. Inform. e-ISSN 2338-5197, 2013.

[14] K. Makkasau, "PENGGUNAAN METODE ANALYTIC HIERARCHY PROCESS (AHP) DALAM PENENTUAN PRIORITAS 
DOI: https://doi.org/10.33330/jurteksi.v6i2.528

Available online at http://jurnal.stmikroyal.ac.id/index.php/jurteksi

PROGRAM KESEHATAN
(STUDI KASUS PROGRAM
PROMOSI KESEHATAN),"
J $@$ TI UNDIP J. Tek. Ind.,
2013,

10.12777/jati.7.2.105-112.

[15] "The analytic hierarchy process," Eur. J. Oper. Res., 1990, doi: 10.1016/03772217(90)90209-t.

[16] R. F. Wijaya, R. B. Utomo, D. Y. Niska, and K. Khairul, "Aplikasi Petani Pintar Dalam Monitoring Dan Pembelajaran Budidaya Padi Berbasis Android," Rang Tek. J., vol. 2, no. 1, pp. 1-4, 2019, doi: 10.31869/rtj.v2i1.1093. 